\title{
HIDRÓLISE ENZIMÁTICA DE CASCA DE ARROZ UTILIZANDO-SE CELULASES. EFEITO DE TRATAMENTOS QUÍMICOS E FOTOQUÍMICOS
}

\author{
Juan Reyes, Patricio Peralta-Zamora e Nelson Durán \\ Instituto de Química - UNICAMP - CP 6154 - 13083-970 - Campinas - SP
}

Recebido em 22/1/97; aceito em 23/7/97

\begin{abstract}
ENZYMATIC HYDROLYSIS OF RICE HULL USING CELLULASES. EFFECT OF CHEMICAL AND PHOTOCHEMICAL TREATMENTS. In the present work we reported the study of rice hull enzymatic hydrolysis using a commercial cellulase preparation. The results showed that previous treatment with light and sodium chlorite inhibits the enzymatic process $(31.4$ and $11.8 \%$, respectively) while hydrogen peroxide and ozone favoured the enzymatic production of reducing sugars (5.9 and $54.9 \%$, respectively). Studies performed by quimiluminescence showed that the chlorite treatment produced the most significant change in the structure of rice hull. Nevertheless, this treatment did not favour the subsequent enzymatic process. Photomicrographs obtained from rice hull hydrolysates showed that pre-treatment changed mainly the inner epidermis and parenchyma cell and that they did not change cellular organization of the hull.
\end{abstract}

Keywords: rice hull; enzymatic saccharification; cellulase.

\section{INTRODUÇÃO}

Nos dias de hoje, caracterizados por um crescimento exacerbado da população e pela exploração indiscriminada dos recursos naturais, observa-se uma clara tendência de esgotamento de recursos. A partir deste fenômeno é possível prever, para um curto prazo, a falta de elementos essenciais para a subsistência humana, especialmente alimentos e combustíveis. Neste sentido, parece claro que a biomassa (primária e residual) será num futuro muito próximo, a principal fonte de recursos para a obtenção de alimentos, produtos químicos e combustíveis ${ }^{1}$. Dentro deste contexto, os materiais lignocelulósicos ocupam um lugar de destaque, principalmente em função da sua abundância e do seu caráter renovável, fatores que tem propiciado um grande interesse por este tipo de material. Resíduos lignocelulósicos caracterizam-se pelo seu baixo conteúdo de proteínas e digestibilidade, o que dificulta a sua utilização como alimento animal no seu estado original. Por este motivo, a utilização de tratamentos prévios, que permitam aumentar a sua digestibilidade e valor nutritivo, é absolutamente essencial. A maior dificuldade para o aproveitamento dos resíduos lignocelulósicos está representada pela barreira física formada pela lignina, o que impede o aproveitamento da celulose nativa. Vários tipos de pré-tratamentos podem ser aplicados com o objetivo de diminuir o teor de lignina e facilitar a posterior hidrólise enzimática por celulases.

Em 1970, a produção anual de casca de arroz nos Estados Unidos foi estimada em um milhão de toneladas ${ }^{2}$, sendo que o seu principal destino era a queima ou simplesmente o seu acúmulo. Pesquisas destinadas a investigar o potencial deste material foram bastante populares na década de 60. Grande parte destes estudos estavam orientados a explorar algumas interessantes propriedades da casca de $\operatorname{arroz}^{2}$ (ex. caráter combustível, abrasivo, isolante, etc.) ou das cinzas obtidas na sua combustão ${ }^{2}$ (ex. propriedades adsorventes, absorventes, filtrantes, etc.). Estudos mais recentes envolvem a utilização de casca de arroz na obtenção de combustível gasoso ${ }^{3}$ e álcool ${ }^{4}$, e a utilização das suas cinzas como adsorvente de óleos ${ }^{5}$, aditivo em concreto ${ }^{6}$ e materiais poliméricos ${ }^{7,8}$. Pesquisas relacionadas com a obtenção de produtos de maior valor agregado são bastante escassas e geralmente envolvem a produção de ácido acético, metanol e acetona, através de processo de destilação a $\operatorname{seco}^{2}$ e produção de xilose por hidrólise ácida ${ }^{2}$. Embora alguns esforços tenham sido dedicados ao estudo de aplicações para a casca de arroz, atualmente não existem projetos industriais que visem a sua exploração em grande escala ${ }^{2}$.

No presente trabalho, encontra-se descrito o efeito de vários tipos de pré-tratamento, químicos (ozônio, clorito de sódio e peróxido de hidrogênio) e fotoquímicos, sobre a composição química da casca de arroz e sua subsequente susceptibilidade à sacarificação enzimática.

\section{MATERIAIS E MÉTODOS}

\subsection{Reagentes}

A celulase comercial (Sigma) e outros reagentes e solventes utilizados foram de grau analítico, e não sofreram nenhuma etapa de purificação prévia.

\subsection{Procedimentos}

\section{Pré-extração da casca de arroz}

A casca foi inicialmente lavada abundantemente com água, seca em estufa, moída e peneirada. Visando-se a eliminação de substâncias que não fazem parte da parede celular (ácidos graxos, resinas, ceras, corantes, etc), a fração de tamanho inferior a 48 mesh foi posteriormente extraída durante $48 \mathrm{~h}$ em extrator Soxhlet, utilizando-se benzeno-etanol 1:1 $(\mathrm{v} / \mathrm{v})$. O resíduo sólido foi seco a massa constante e mantido em dessecador.

\section{Pré-tratamento por irradiação}

A casca de arroz foi irradiada utilizando-se uma lâmpada de vapor de mercúrio (HQL-Osram), sem o vidro protetor, colocada a $17 \mathrm{~cm}$ de altura, sobre uma placa de vidro (20x20) que continha uma monocamada de amostra.

As velocidades de fluência proporcionadas pela lâmpada foram determinadas por meio de um radiômetro (YSI-Kettering, modelo 65A), obtendo-se os valores de $68,4 \mathrm{~W} \mathrm{~m}^{-2}$ (para $\lambda \geq$ $300 \mathrm{~nm}$ ) e $108,0 \mathrm{~W} \mathrm{~m}^{-2}$ (para $\lambda \geq 254 \mathrm{~nm}$ ). Nas irradiações a $\lambda$ $\geq 300 \mathrm{~nm}$, utilizou-se um filtro Pyrex refrigerado a água. 


\section{Pré-tratamento com $\mathrm{H}_{2} \mathrm{O}_{2}$ em meio básico 9}

1,00 g de casca de arroz foi suspensa em $50 \mathrm{~mL}$ de água oxigenada $1 \%(\mathrm{v} / \mathrm{v})$. $\mathrm{O} \mathrm{pH}$ desta suspensão foi ajustado em 11,5 com solução aquosa de hidróxido de sódio e deixou-se em agitação durante $24 \mathrm{~h}$. O material sólido foi posteriormente lavado com água destilada até $\mathrm{pH}$ neutro, seco até massa constante e mantido em dessecador.

\section{Pré-tratamento com ozônio ${ }^{10}$}

A casca de arroz foi colocada numa coluna cromatográfica de $80 \mathrm{~cm}$ de comprimento e $1 \mathrm{~cm}$ de diâmetro interno, através da qual passou-se ozônio durante $48 \mathrm{~h}$ (de baixo para cima) com vazão de aproximadamente 100 bolhas por minuto.

\section{Pré-tratamento com clorito de sódio ${ }^{11}$}

A casca de arroz foi suspensa em solução de clorito de sódio $0,4 \%\left(\mathrm{v} / \mathrm{v}\right.$, em ácido acético glacial ) a $80-90^{\circ} \mathrm{C}$, e agitada magneticamente durante $2 \mathrm{~h}$. A relação casca:solução foi de 2:100 (v/v).

\section{Análise química da casca de arroz}

A determinação de celulose (livre de lignina, hemicelulose e cinza) foi realizada de acordo com procedimentos descritos por Updegraff ${ }^{12}$. O procedimento envolve etapas de tratamento com reagente de Crampton/Maynard (ácido acético-ácido nítrico), hidrólise em ácido sulfúrico a $67 \%$ e formação de um composto colorido por reação com solução de antrona. A absorvância do produto formado é medida em $620 \mathrm{~nm}$ (espectrofotômetro Baush Lomb, Spectronic 2000), enquanto que a concentração de celulose é determinada a partir de uma curva de calibração realizada com um padrão de celulose, obtido por dissolução de papel Whatman $\mathrm{N}^{\mathrm{o}} 1$ em ácido sulfúrico a $67 \%$. $\mathrm{O}$ teor de lignina total foi obtido a partir da soma dos valores de concentração de lignina Klason ${ }^{13}$ e lignina solúvel em ácido $^{11}$. O teor de cinzas foi obtido por calcinação da amostra durante $2 \mathrm{~h}$ a $600^{\circ} \mathrm{C}$. O teor de hemicelulose encontra-se incluído no parâmetro identificado como "outros", o qual foi obtido por diferença (subtraindo-se a soma das massas de celulose, lignina total e cinza da massa da amostra).

Medidas de quimiluminiscência foram realizadas em $50 \mathrm{mg}$ de material sólido, suspensos em $1 \mathrm{~mL}$ de hidróxido de sódio 5 M. As medidas foram realizadas em um contador de cintilação Beckman LS-7000.

Micrografias eletrônicas foram obtidas utilizando-se um microscópio eletrônico de reflexão JEOL JSM-P15.

\section{Sacarificação enzimática da casca de arroz. Determinação de açúcares redutores ${ }^{14}$}

A $50 \mathrm{mg}$ de casca de arroz (peso seco) foram adicionados $0,5 \mathrm{~mL}$ de solução de celulase $\left(1,5 \mathrm{~g} \mathrm{~L}^{-1}\right.$, atividade contra papel de filtro Whatman $\left.\mathrm{N}^{\mathrm{o}} 1: 251 \mathrm{UL}^{-1}\right)$ e $1,0 \mathrm{~mL}$ de tampão citrato $0,05 \mathrm{M}(\mathrm{pH} \mathrm{4,8)}$ e a mistura foi deixada em banho-maria a $50^{\circ} \mathrm{C}$ durante $1 \mathrm{~h}$. Acrescentou-se $3 \mathrm{~mL}$ de solução de ácido 3,5-dinitrossalicílico, ferveu-se a mistura durante 5 min e acrescentou-se $16 \mathrm{~mL}$ de água destilada. A mistura foi centrifugada a $2000 \mathrm{rpm}$ durante $5 \mathrm{~min}$ e a absorvância da solução colorida sobrenadante medida em $550 \mathrm{~nm}$, contra branco de reagentes. A massa de açúcares redutores foi determinada a partir de uma curva de calibração, preparada a partir de uma solução de glicose em tampão citrato $0,05 \mathrm{M}(\mathrm{pH} 4,8)$.

\section{RESULTADOS E DISCUSSÃO}

O complexo celulase envolve no mínimo três enzimas, as quais apresentam modos de ação bastante característicos. $\beta$-1,4-glicano-glicanoidrolase (uma endoglicanase), $\beta$-1,4-glicanocelobioidrolase (uma exoglicanase) e $\beta$-1,4-glicosidase (uma celobiase $)^{15}$. As primeiras clivam celulose nativa ao acaso, possibilitando a formação de cadeias menores de celotriose, celobiose e glicose, enquanto que as segundas atuam nas extremidades não redutoras das cadeias, separando moléculas de celobiose. Finalmente as glicosidases hidrolisam celobiose a glicose.

Como o substrato é insolúvel em solução aquosa as enzimas terão que dirigir-se à sua superfície onde, após adsorvidas, poderão reagir. Desta maneira, o processo enzimático é heterogêneo, o que faz com que os efeitos difusionais sejam tão importantes quanto os cinéticos ${ }^{15}$.

Em função destes fatos, dois fatores são fundamentais para a hidrólise enzimática com celulases:

1. A natureza das enzimas

2. A natureza do substrato

Por outro lado, nas fibras de celulose coexistem regiões de alta cristalinidade e regiões amorfas menos organizadas. Quanto maior for a proporção da forma cristalina, maior a resistência ao ataque enzimático ${ }^{16}$. Deste modo, os sistemas de prétratamento, além de permitir a deslignificação do material, podem diminuir a cristalinidade da celulose, podendo ser fundamentais para o decorrer do ataque enzimático subsequente.

Embora a luz ultravioleta apresente baixa capacidade para penetrar em materiais celulósicos (aproximadamente $75 \mu \mathrm{m}$ ), a sua capacidade para promover a oxidação de lignina é bem conhecida ${ }^{17}$. Entre os vários grupos funcionais característicos da lignina (grupos fenólicos, duplas ligações e grupos carbonila), as carbonilas conjugadas ao anel aromático parecem ser os cromóforos mais efetivos para dar início ao processo de fotodegradação.

O pré-tratamento que utiliza peróxido de hidrogênio em meio básico deve seu poder oxidante ao altamente reativo radical hidroxila ${ }^{18}$, gerado na reação do peróxido de hidrogênio com o ânion hidroperóxido (eq. 1):

$\mathrm{H}_{2} \mathrm{O}_{2}+\mathrm{HOO}^{-} \longrightarrow \mathrm{HO}^{*}+\mathrm{O}_{2}{ }^{{ }_{-}}+\mathrm{H}_{2} \mathrm{O}$

A reação acima é dependente do $\mathrm{pH}$ do meio, em função do ânion hidroperóxido ser formado na dissociação do peróxido de hidrogênio (eq. 2):

$\mathrm{H}_{2} \mathrm{O}_{2} \rightleftharpoons \mathrm{HOO}^{-}+\mathrm{H}^{+}$

A utilização de processos de pré-tratamento com ozônio é bastante freqüente na indústria de papel e celulose, principalmente em função do seu elevado poder branqueador e da sua natureza não-poluente. $\mathrm{O}$ mecanismo de degradação de lignina não está totalmente esclarecido. Sabe-se, entretanto, que reações de hidroxilação ${ }^{19}$, quebra oxidativa de grupos metoxila ${ }^{20}$ e abertura de anel ${ }^{21}$, são freqüientes na reação entre ozônio e compostos modelo de lignina.

Processos de deslignificação utilizando-se clorito de sódio estão baseados na reação entre lignina e $\mathrm{ClO}_{2}, \mathrm{ClO}^{-}$, produtos estes formados em reações redox de $\mathrm{ClO}_{2}^{-}$em meio ácido (eq. 3):

$8 \mathrm{ClO}_{2}^{-}+6 \mathrm{H}^{+} \longrightarrow 6 \mathrm{ClO}_{2}+\mathrm{ClO}^{-}+\mathrm{Cl}^{-}+3 \mathrm{H}_{2} \mathrm{O}$

As reações entre lignina e $\mathrm{ClO}_{2}$ são exclusivamente oxidativas, levando à formação de derivados do ácido mucônico e quinona.

Em função das características acima comentadas, cada processo de pré-tratamento proposto apresenta características que podem ser exploradas na deslignificação da casca de arroz, de maneira a favorecer posteriores etapas de hidrólise enzimática. $\mathrm{Na}$ tabela 1 apresentam-se os resultados que ilustram o efeito de cada processo de pré-tratamento na composição química básica da casca de arroz. Observa-se, a partir destes resultados, que o tratamento mais eficiente para a redução do teor de lignina está representado pela utilização de clorito de sódio (redução de aproximadamente $45 \%$ ). A redução observada para os outros processos foi pouco significativa e bastante próxima 
Tabela 1. Efeito do pré-tratamento sobre a composição química da casca de arroz.

\begin{tabular}{cllcr}
\hline Tratamento & $\begin{array}{c}\text { Celulose } \\
(\%)\end{array}$ & \multicolumn{1}{c}{$\begin{array}{c}\text { Lignina } \\
(\%)\end{array}$} & \multicolumn{1}{c}{$\begin{array}{c}\text { Cinzas } \\
(\%)\end{array}$} & $\begin{array}{c}\text { Outros }^{(1)} \\
(\%)\end{array}$ \\
\hline Nenhum & $38,4 \pm 2,8^{(2)}$ & $29,4 \pm 5,9^{(2)}$ & $8,5 \pm 1,8^{(2)}$ & 23,7 \\
Irradiação & $33,9 \pm 3,4$ & $31,8 \pm 5,1$ & $10,1 \pm 1,7$ & 24,2 \\
$\mathrm{H}_{2} \mathrm{O}_{2}$ & $53,2 \pm 3,2$ & $28,0 \pm 4,5$ & $10,6 \pm 1,7$ & 8,2 \\
$\mathrm{Ozônio}$ & $41,6 \pm 3,9$ & $28,9 \pm 4,7$ & $10,7 \pm 2,2$ & 18,8 \\
$\mathrm{ClO}_{2}{ }^{-}$ & $39,6 \pm 4,2$ & $16,1 \pm 4,8$ & $11,2 \pm 2,6$ & 33,1 \\
\hline
\end{tabular}

(1) Valor obtido por diferença: (massa total - (celulose+ lignina + cinzas)); (2) Desvio Padrão de determinação feita em duplicata.

do erro experimental para esta determinação. É interessante salientar o importante acréscimo experimentado pela concentração de celulose (aproximadamente 39\%), quando o tratamento é realizado com peróxido de hidrogênio. Tal resultado indicaria que significativas quantidades de hemicelulose estão sendo transformadas e/ou eliminadas do sistema, o que é bastante conveniente já que permite um aumento da quantidade relativa do substrato de interesse. Pelo fato do teor de hemicelulose ser obtido por diferença, é bastante difícil elaborar alguma explicação para a sua decomposição.

A quimiluminiscência é uma técnica que apresenta bastante utilidade no esclarecimento de modificações estruturais em biomoléculas, podendo ser usada, portanto, na verificação das mudanças estruturais sofridas pelo material após aplicação dos diversos processos de pré-tratamento. A lignina, quando em solução neutra, não é quimiluminiscente, mas apresenta importante emissão quando em meio básico. As espécies responsáveis pela quimiluminiscência parecem ser oxigênio singlete e carbonilas excitadas, espécies que têm sido detectadas em espectros de emissão de compostos modelo ${ }^{22}$ (ex: vanilina, ácido vanílico, etc.). Os resultados apresentados na figura 1 , obtidos por irradiação da casca de arroz em $\lambda \geq 300 \mathrm{~nm}$, mostram uma emissão significativamente maior para o material submetido a tratamento com clorito de sódio. Este resultado, que sugere uma modificação mais importante na estrutura da lignina, é plenamente coincidente com a importante redução do teor de lignina comentada anteriormente.

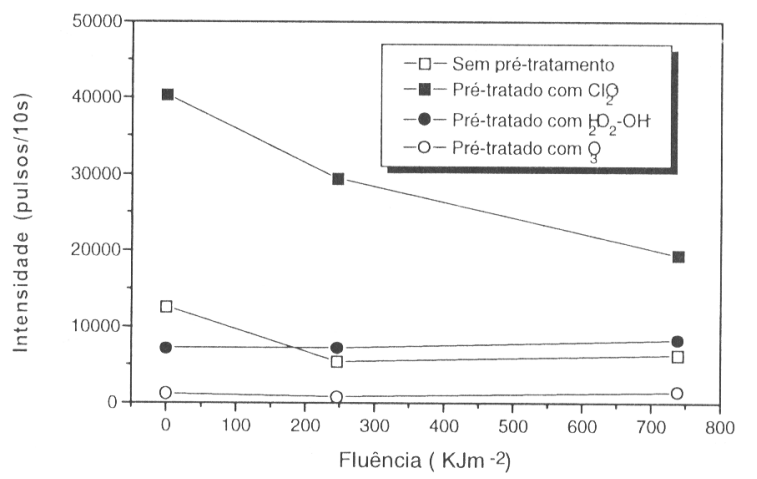

Figura 1. Efeito do pré tratamento sobre a intensidade quimiluminiscente obtida da casca de arroz irradiada a $\lambda \geq 300 \mathrm{~nm}$.

Os resultados obtidos na hidrólise enzimática da casca de arroz, utilizando-se celulase comercial, são apresentados na tabela 2 . Observa-se claramente que, diferentemente do esperado, a maior produção de glicose é obtida quando se utiliza um tratamento prévio com ozônio. O tratamento com clorito de sódio, embora provoque as mudanças mais significativas com relação à lignina, mostrase prejudicial à hidrólise, talvez devido à obtenção de substratos
Tabela 2. Efeito das condições de pré-tratamento sobre a hidrólise enzimática com celulase comercial.

\begin{tabular}{ccc}
\hline Pré-Tratamento & $\begin{array}{c}\text { Massa de Glicose } \\
(\mathrm{mg})\end{array}$ & $\begin{array}{c}\text { Recuperação } \\
(\%)\end{array}$ \\
\hline Nenhum & $0,51 \pm 0,022^{(3)}$ & - \\
Irradiação & $0,35 \pm 0,015$ & $-31,4$ \\
$\mathrm{H}_{2} \mathrm{O}_{2}$ & $0,54 \pm 0,034$ & $+5,9$ \\
$\mathrm{Ozônio}^{(3)}$ & $0,79 \pm 0,025$ & $+54,9$ \\
$\mathrm{ClO}_{2}{ }^{-}$ & $0,45 \pm 0,029$ & $-11,8$ \\
\hline
\end{tabular}

(1) Resultados obtidos no tratamento enzimático de $50 \mathrm{mg}$ de casca de arroz, durante $1 \mathrm{~h}$.

(2) Recuperação de glicose em relação à quantidade obtida sem pré-tratamento.

(3) Desvio Padrão de determinação feita em duplicata.

que inibam parcialmente as celulases. O processo enzimático envolvendo celulases é bastante complexo, podendo ser inibido por vários produtos solúveis originados na própria reação enzimática. Celobiose e glicose, por exemplo, tem sido identificados como inibidores do complexo celulase, enquanto que $\beta$-glicosidase pode também ser inibida pelo seu substrato, celobiose ${ }^{15}$. Por outro lado, existem fortes evidências sobre a significativa redução da atividade da $\beta$-1,4-glicosidase, e inclusive de todo o complexo celulase, quando grupos carbonilas são introduzidos e lactonizados na molécula de substrato ${ }^{23}$. Em função destes antecedentes, da complexidade do substrato e da grande variedade de compostos que podem surgir do pré-tratamento e da posterior reação enzimática, resulta bastante difícil o esclarecimento dos motivos que levam a resultados como os citados anteriormente.

Finalmente, para verificar o efeito físico dos diversos tipos de pré-tratamento, realizaram-se micrografias eletrônicas, algumas das quais são apresentadas nas figuras 2 a 6 . Na figura 2, correspondente a casca de arroz sem tratamento prévio, é possível observar a epiderme externa bem conservada, com estruturas celulares revestidas de sílica. Na figura 3, é possível observar a epiderme externa levemente atingida pelo tratamento com irradiação. Nas figuras 4 e 5, obtidas após tratamento com ozônio e com peróxido de hidrogênio em meio básico, respectivamente, observa-se a epiderme externa bem organizada, mas com fissuras entre as filas celulares. Finalmente, na figura 6, correspondente ao tratamento com clorito de sódio, observa-se a epiderme externa fissurada. De um modo geral é possível observar que, do ponto de vista morfológico, os processos de pré-tratamento parecem afetar igualmente e de maneira branda a casca de arroz. O tratamento não chega a atingir a organização celular, principalmente aquelas camadas que possuem células reforçadas por sílica. Convém salientar, no entanto, que uma interpretação inequívoca do material fotográfico é bastante difícil, em função da heterogeneidade do material estudado.

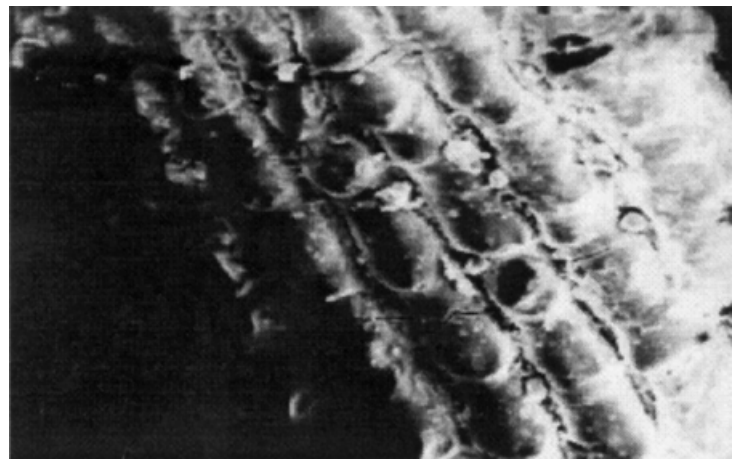

Figura 2. Micrografia da epiderme externa da casca de arroz sem tratamento preevio. 


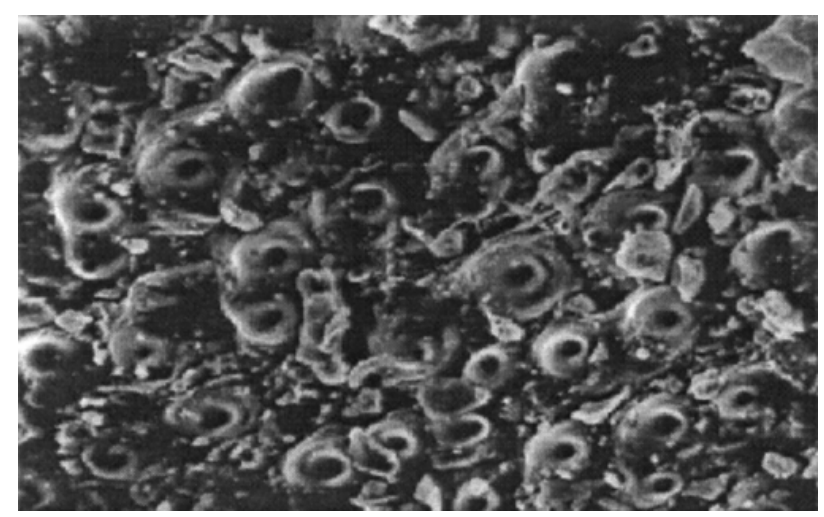

Figura 3. Micrografia da epiderme externa da casca de arroz após pré-tratamento por irradiação.

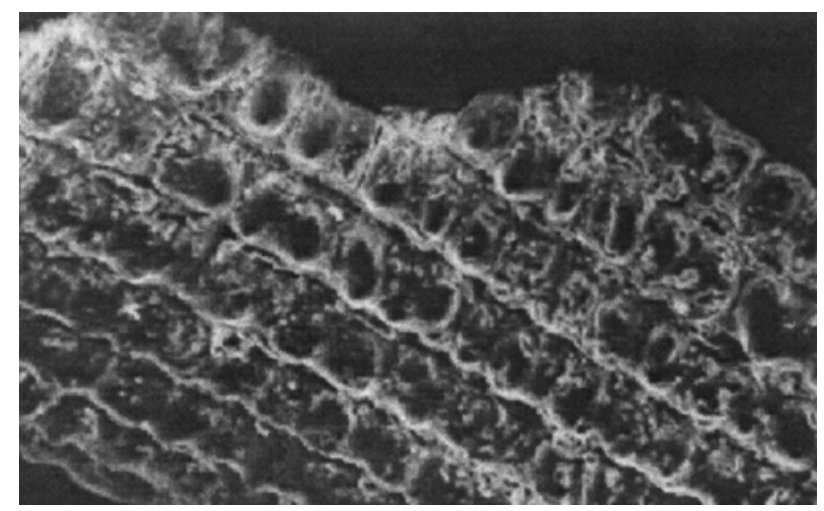

Figura 4. Micrografia da epiderme externa da casca do arroz após pré-tratamento com ozônio.

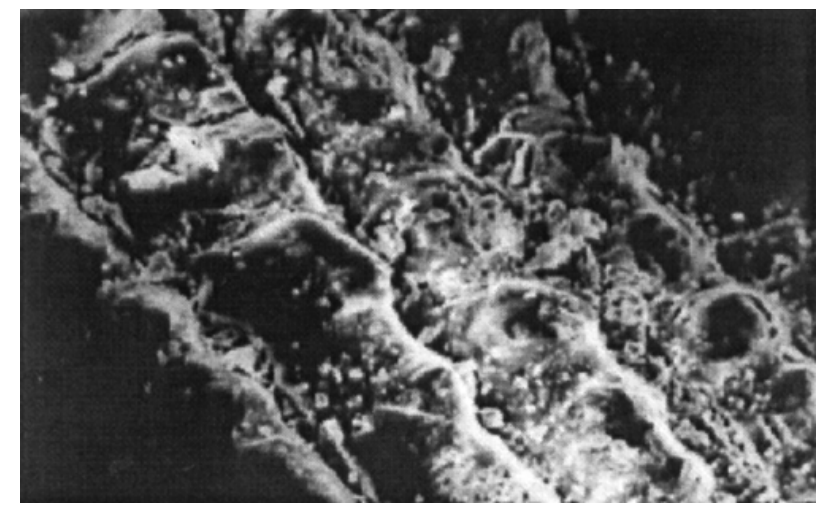

Figura 5. Micrografia da epiderme externa da casca de arroz após pré-tratamento com peróxido de hidrogênio.

\section{CONCLUSÕES}

Em função dos resultados apresentados, pode-se concluir que o tratamento com clorito de sódio apresenta a maior eficiência na deslignificação da casca de arroz, observação que é também sugerida pelos estudos de quimiluminiscência. O posterior processo de hidrólise enzimática, no entanto, não é favorecido pelas mudanças provocadas por este pré-tratamento, provavelmente devido à formação de substratos menos susceptíveis à ação enzimática. $\mathrm{O}$ maior rendimento da hidrólise enzimática foi conseguido com o pré-tratamento com ozônio, enquanto que o tratamento com peróxido de hidrogênio possibilitou um significativo enriquecimento do teor de celulose. Os estudos de micrografia eletrônica parecem indicar que os pré-tratamentos

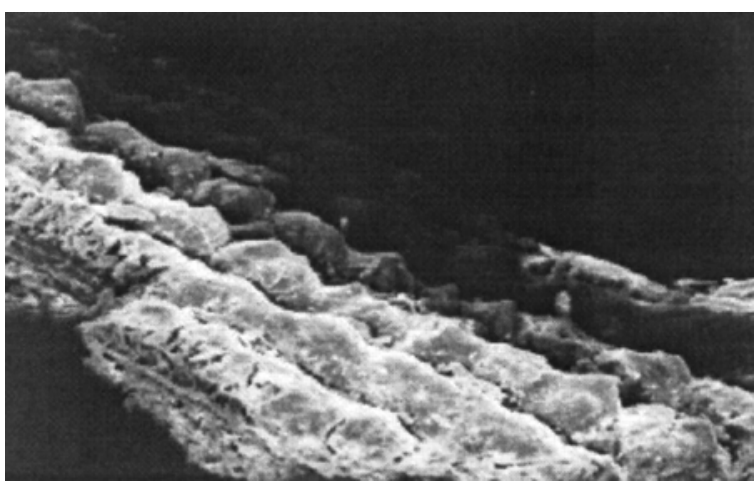

Figura 6. Micrografia da epiderme externa da casca de arroz após pré-tratamento com clorito de sódio.

propostos não conseguem atingir a organização celular da casca de arroz. Saliente-se finalmente que o processo enzimático leva a obtenção de açúcares fermentáveis, que podem ser utilizados na produção de etanol, o que eleva o valor agregado do material em estudo. Embora análises da relação custo-benefício não tenham sido realizadas, a transformação de um resíduo agrícola num material que pode ser utilizado como insumo na produção de combustível parece, numa primeira análise, bastante conveniente.

\section{REFERÊNCIAS}

1. Hacking, A. J.; Economics Aspects of Biotechnology. Cambridge, University Press, 1986.

2. Yokoya, F. Rice Hull utilization. Western Utilization Research \& Development, Division Agricultural Research Service U. S.; Department of Agriculture. 1970, URS 776-10.

3. Stickney, R. E.; Appropiate Technol. 1989, 16, 14.

4. Moniruzzaman, N.; Bioresource Technol. 1996, 55, 111.

5. Saleh, M. I. and Adam, R.; J. Am. Oil Chem. Soc. 1994, $71,1363$.

6. Zhang, M. H.; Cement and Concrete Research 1996, 26, 963.

7. Ishak, Z. A. M. and Bakar, A. A.; European Polymer J. 1995, 31, 259.

8. Fuad, M. Y. A.; Ismail, Z.; Ishak, Z. A. M. and Omar, A. K. M.; European Polymer J. 1995, 31, 885.

9. Gould, J. M.; Biotechnol. Bioeng. 1984, 26, 46.

10. Shefet, G. and Ben-Ghedalia, D.; Eur. J. Appl. Microbiol. Biotechnol 1982, 15, 47.

11. Taniguchi, M.; Tanaka, M.; Matsuno, R. and Kamikubo, T.; Eur. J. Appl. Microbiol. Biotechnol. 1982, 14, 35.

12. Updegraff, D. M.; Anal. Biochem. 1969, 32, 420.

13. Padrão TAPPI, T13m-54

14. Mandels, M.; Andreotti, R. and Roche, C.; Biotechnol Bioeng. 1976, 6, 21.

15. Ladisch, M. R.; Lin, K. W.; Voloch, M. and Tsao, G. T.; Enzyme microb. Technol. 1983, 5, 82.

16. Robson, L. M and Chambliss, G. E.; Enzyme microb. Technol. 1989, 11, 626.

17. Durán, N.; Mansilla, H. and Reyes, J.; J. Photochem. 1986, 35, 209.

18. Gould, J. M.; Biotechnol. Bioeng. 1984, 26, 46.

19. Moeller, H. W. and Treoesch, W.; Appl. Microbiol. Biotechnol. 1986, 24, 180.

20. Boyles, D. T.; J. Chem. Tech. Biotechnol. 1986, 36, 495.

21. Pyle, D. L. and Zaror, C. A.; Chem. Eng. Sci. 1984, 39, 147.

22. Durán, N. and Mansilla, H.; J. Macromol. Sci. Chem. 1984, A21, 1467.

23. Bruchmann, E. E.; Schach, H. and Graf H.; Biotechnology and Applied Biochemistry 1987, 9, 146. 